\title{
L-Arginine in Combination With Sildenafil Potentiates the Attenuation of Hypoxic Pulmonary Hypertension in Rats
}

\author{
H. AL-HITI ${ }^{1}$, M. CHOVANEC ${ }^{2,3}$, V. MELENOVSKÝ ${ }^{1}$, O. VAJNEROVÁ ${ }^{3}$, A. BAŇASOVÁ ${ }^{4}$, \\ J. KAUTZNER ${ }^{1}$, J. HERGET ${ }^{3}$
}

${ }^{1}$ Department of Cardiology, Institute for Clinical and Experimental Medicine, Prague, ${ }^{2}$ Department of Cardiology, Na Homolce Hospital, Prague, ${ }^{3}$ Department of Physiology and ${ }^{4}$ Department of Pathophysiology, Second Medical School, Charles University, Prague, Czech Republic

Received September 6, 2012

Accepted March 21, 2013

On-line July 17, 2013

\section{Summary}

Chronic hypoxia induces an increased production of nitric oxide (NO) in pulmonary prealveolar arterioles. Bioavailability of the NO in the pulmonary vessels correlates with concentration of Larginine as well as activity of phosphodiesterase- 5 enzyme (PDE5). We tested a hypothesis whether a combination of L-arginine and PDE-5 inhibitor sildenafil has an additive effect in reduction of the hypoxic pulmonary hypertension ( $\mathrm{HPH}$ ) in rats. Animals were exposed to chronic normobaric hypoxia for 3 weeks. In the $\mathrm{AH}$ group, rats were administered L-arginine during chronic hypoxic exposure. In the $\mathrm{SH}$ group, rats were administered sildenafil during chronic hypoxic exposure. In the SAH group, rats were treated by the combination of L-arginine as well as sildenafil during exposure to chronic hypoxia. Mean PAP, structural remodeling of peripheral pulmonary arterioles (\%DL) and $\mathrm{RV} / \mathrm{LV}+\mathrm{S}$ ratio was significantly decreased in the SAH group compared to hypoxic controls even decreased compared to the $\mathrm{AH}$ and the $\mathrm{SH}$ groups in first two measured parameters. Plasmatic concentration of CGMP and NOx were significantly lower in the SAH group compared to hypoxic controls. We demonstrate that NO synthase substrate L-arginine and phosphodiesterase-5 inhibitor sildenafil administered in combination are more potent in attenuation of the $\mathrm{HPH}$ compared to a treatment by substances given alone.

\section{Key words}

Pulmonary hypertension • Chronic hypoxia • L-arginine • Sildenafil

\section{Corresponding author}

Milan Chovanec, Department of Physiology, Second Medical
School, Charles University, Plzenska 130/221, 15000 Prague, Czech Republic. E-mail: milan.chovanec@lfmotol.cuni.cz

\section{Introduction}

Morbidity and mortality of pulmonary arterial hypertension (PAH) still remains high. The production of nitric oxide (NO) in pulmonary arterioles increases during exposure to chronic hypoxia (Hampl et al. 1993, Xue et al. 1994). It suggests NO has an important role in the adaptation of the pulmonary circulation to elevated blood pressure. The production of NO in the pulmonary vessels is related to the concentration of L-arginine as a substrate for NO synthesis (Palmer et al. 1988, Stuehr et al. 1991). It is reported that administration of L-arginine increases NO production (Fike et al. 2000) as well as decreases pulmonary hypertension caused by chronic hypoxia (hypoxic pulmonary hypertension, HPH) (Mitani et al. 1997). Nitric oxide in smooth muscle cells binds to soluble guanylate cyclase and activates the production of cyclic guanosine monophosphate (cGMP). Cyclic GMP activates processes which result in the activation of voltage-gated potassium channels and inhibition of the depolarization of the smooth muscle cells and thus leads to vasodilation (Murad 1986, Archer et al. 1994). The soluble cGMP is degraded by the phosphodiesterase (PDE) enzyme (specific isoform number 5) in pulmonary arterioles. Inhibition of PDE activity by sildenafil has a significant vasodilatory effect in the developed HPH in rats (Cohen et al. 1996) and also in patients with pulmonary arterial hypertension (PAH) (Michelakis et al. 
2002). The effective vasodilatory therapy has been considered an important factor in improving quality of life in patients with PAH (D'Alonzo et al. 1991). The PDE inhibitors are used most often in combination with other drugs in treatment of PAH: in combination with prostacycline analogues (Itoh et al. 2004, Clozel et al. 2006), in combination with endothelin receptor A inhibitors (Mouchaers et al. 2009), and in combination with HMG-CoA inhibitors (Satoh and Satoh 2008, Zhao et al. 2009). Every used combination has a moderate potentiation effect in decreasing the pulmonary artery pressure compared to the PDE inhibitor alone.

In the present study in rats, we tested the hypothesis whether the combination of L-arginine and the PDE-5 inhibitor sildenafil is more effective in reduction of the development of HPH than the drugs administered alone.

\section{Methods}

Experiments on five groups of adult male Wistar rats (BW 220-250 $\mathrm{g}$ at the beginning of the experiment) were performed in accordance with the European Community and NIH guidelines for the use of experimental animals. All experiments were approved by our institution's Animal Studies Committee.

\section{Experimental groups and drug administration}

Experimental animals were exposed to chronic hypoxia in an isobaric hypoxic chamber $\left(\mathrm{F}_{\mathrm{iO} 2}=0.1\right)$ for 3 weeks. Experimental group $\mathrm{AH}(\mathrm{n}=10)$ were rats administered with L-arginine (Sigma-Aldrich ${ }^{\circledR}$, Czech Republic), 500 mg. $\mathrm{kg}^{-1}$ per day by gavage during hypoxia exposition. We used a similar effective dose of L-arginine as other researchers (Mitani et al. 1997). Group SH $(n=10)$ were rats administered with the PDE-5 inhibitor sildanefil (Revatio $20 \mathrm{mg}$ tbl, Pfizer ${ }^{\circledR}$ ), $25 \mathrm{mg} \cdot \mathrm{kg}^{-1}$ per day by gavage during hypoxia. In the literature, the dosage of sildenafil varies from $1 \mathrm{mg} \cdot \mathrm{kg}^{-1}$ to $100 \mathrm{mg} \cdot \mathrm{kg}^{-1}$ per day or more (Preston et al. 2004, Clozel et al. 2006, Satoh and Satoh 2008, Zhao et al. 2009). We decided to use a lower dose of sildenafil (25 mg. $\mathrm{kg}^{-1}$ per day) to unmask the potentially amplifying effect of L-arginine. Group SAH $(n=10)$ were rats given a combination of L-arginine and sildenafil during hypoxia. Group $\mathrm{H}(\mathrm{n}=10)$ were rats exposed to chronic hypoxia with no drugs. Group N ( $n=10)$ were normoxic controls. All animals lived in 12 hours diurnal cycles and had free access to water and food. The gavage technique was used to avoid the influence of food and water intake decrease during hypoxic exposure (Singh and Selvamurthy 1993).

\section{Experimental protocol and measurements}

After 3 weeks of hypoxia, rats were anesthetized with thiopental (30 mg. $\mathrm{kg}^{-1}$ b.w. i.p.). In closed-chest spontaneously breathing animals, we measured the mean pulmonary artery pressure (PAP) (Herget and Palecek 1972). After measurement of PAP, the animals were ventilated with air through a tracheal cannula (50 breaths. min $^{-1}$; peak inspiratory pressure $10 \mathrm{~cm} \mathrm{H}_{2} \mathrm{O}$; positive end-expiratory pressure $2 \mathrm{~cm} \mathrm{H}_{2} \mathrm{O}$ ). The chest was then opened by sternotomy and an ultrasound flow probe with J transducer (Transonic Systems Inc, Ithaca, NY, USA) was placed on the ascending aorta to measure cardiac output (Hampl et al. 1993). Subsequently, arterial blood samples were collected for measuring cGMP and hematocrit. The plasma concentration of $\mathrm{NO}$ and its oxidation products (nitrites and nitrates, NOx) were measured with a chemiluminescence NO analyzer using the methods described earlier (Sun et al. 2010). Finally, the heart and lungs were removed from the thoracic cavity. The heart was dissected and weighed in parts (Fulton et al. 1952). Lungs were filled with formol solution through the trachea for assessing the presence of hypoxia-induced structural remodeling of peripheral pulmonary arteries. The same person blinded to the study group from which the specimen originated calculated all scores. The results are presented as the proportion of peripheral vessels with separated elastic laminas (doublelaminated, \%DL) (Herget et al. 1978).

Cyclic GMP was determined from blood samples which were frozen and stored at $-80{ }^{\circ} \mathrm{C}$ until measurement was performed by the radioimmunoassay kit (Immunotech Inc).

\section{Statistical analysis}

Results were analyzed by 1-way ANOVA with Fischer post-hoc test. Values of $\mathrm{p}<0.05$ were considered significant. The results are presented as means \pm SEM.

\section{Results}

Body weight, cardiac output and hematocrit did not differ in any of the groups exposed to chronic hypoxia (Table 1). Plasma concentration of cGMP was increased in all groups exposed to hypoxia compared to normoxic controls, however, rats administered by L- 
arginine and a combination of L-arginine with sildenafil had a significantly higher cGMP concentration than hypoxic controls (Table 1). The group with combined treatment had significantly higher concentrations of nitrites and nitrates (NOx) compared to all other groups (Table 1).

Table 1. Body weight, cardiac output, hematocrit and plasmatic concentration of cGMP and NOx.

\begin{tabular}{|c|c|c|c|c|c|}
\hline & $\begin{array}{l}\text { BW } \\
\text { (g) }\end{array}$ & $\begin{array}{l}\text { CO } \\
\left(\text { ml.min }^{-1}\right)\end{array}$ & $\begin{array}{l}\text { HTC } \\
(\%)\end{array}$ & $\begin{array}{l}\text { cGMP in plasma } \\
\left(\mathrm{pM} . .^{-1}\right)\end{array}$ & 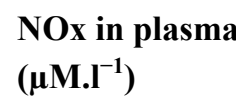 \\
\hline$N$ & $405.6 \pm 33.3$ & $34.3 \pm 7.2$ & $43.4 \pm 3.7$ & $0.1 \pm 0.04$ & $21.4 \pm 2.8$ \\
\hline$H$ & $274.4 \pm 22.4 *$ & $20.0 \pm 3.7 *$ & $68.4 \pm 4.6 *$ & $73.5 \pm 27.8 *$ & $27.3 \pm 4.7$ \\
\hline$A H$ & $263.4 \pm 24.3 *$ & $21.7 \pm 1.5 *$ & $64.8 \pm 7.5 *$ & $101.6 \pm 31.6 *^{+}$ & $27.8 \pm 2.2$ \\
\hline SH & $253.2 \pm 11.6^{*^{+}}$ & $25.8 \pm 5.9^{\#}$ & $72.5 \pm 3.8 *$ & $95.6 \pm 26.1 *$ & $22.5 \pm 1.5$ \\
\hline$S A H$ & $258.0 \pm 18.0 *$ & $22.6 \pm 6.0 *$ & $70.0 \pm 5.8 *$ & $113.3 \pm 29.5 *^{+}$ & $38.0 \pm 4.4^{*}$ \\
\hline
\end{tabular}

BW - body weight in time of measurement; CO - cardiac output; HTC - hematocrit; CGMP - cyclic guanosine monophosphate. $* \mathrm{P}<0.0001$ vs. group $\mathrm{N} ; \# \mathrm{P}<0.01$ vs. group $\mathrm{N}^{+} \mathrm{P}<0.05$ vs. group $\mathrm{H}$. $\neq \mathrm{P}<0.05$ vs. all other groups.

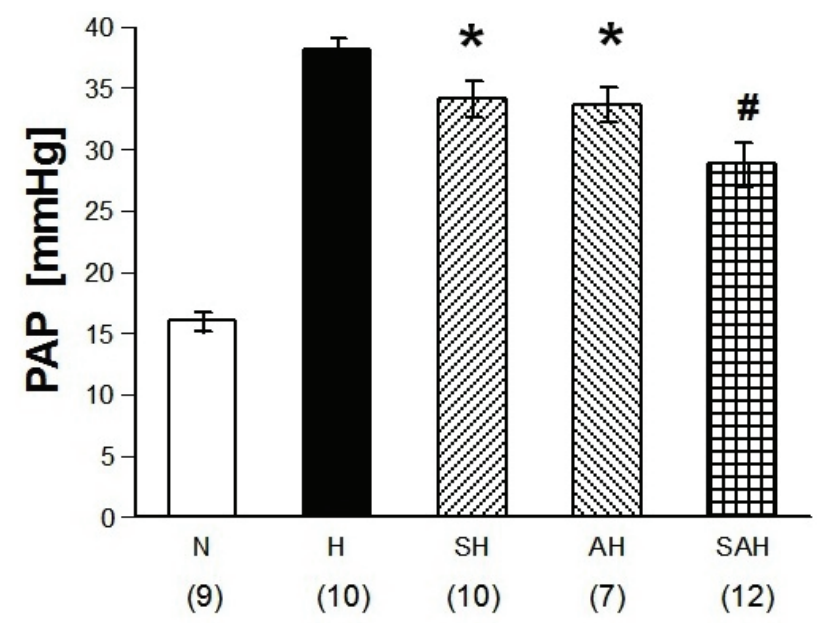

Fig. 1. Pulmonary arterial mean pressure. $\mathrm{N}$ - normoxic controls, ambient air $\mathrm{H}$ - hypoxic controls, 3 wks of hypoxia, $\mathrm{SH}-$ hypoxia exposure for 3 wks and sildenafil administration; $\mathrm{AH}$ - hypoxia exposure for 3 wks and L-arginine administration; SAH - hypoxia for 3 wks and sildenafil plus L-arginine administration. $* p<0.05$ vs. group $\mathrm{H} ; \# p<0.0001$ vs. group $\mathrm{H}$ and $\mathrm{p}<0.05$ vs. groups $\mathrm{SH}$ and $\mathrm{AH}$. Data are means \pm SEM, numbers of rats are in parentheses.

Animals exposed to hypoxia with administration of drugs had significantly lower mean PAP compared to non-treated hypoxic rats. Mean PAP in the SAH group was significantly lower compared to the groups administered with L-arginine or sildenafil alone (Fig. 1). We found the right heart ventricle weight was significantly reduced in the SAH group compared to the $\mathrm{H}$ group, but not in the $\mathrm{AH}$ and $\mathrm{SH}$ groups (Fig. 2). Presence of the double laminated pulmonary arterioles was significantly lower in the groups exposed to hypoxia with administration of drugs compared to hypoxic controls, but the SAH group had significantly lower \%DL compared to the $\mathrm{AH}$ and $\mathrm{SH}$ groups (Fig. 3).

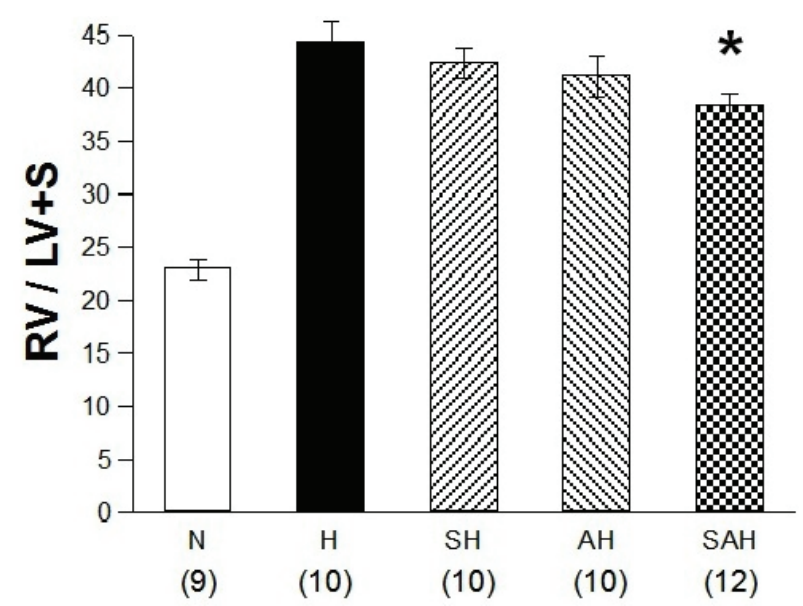

Fig. 2. Right ventricular heart weight to the sum of weights of left heart ventricle and septum ratio. $\mathrm{N}$ - normoxic controls, ambient air $\mathrm{H}$ - hypoxic controls, 3 wks of hypoxia, $\mathrm{SH}-$ hypoxia exposure for 3 wks and sildenafil administration; $A H$ - hypoxia exposure for $3 \mathrm{wks}$ and L-arginine administration; SAH - hypoxia for $3 \mathrm{wks}$ and sildenafil plus L-arginine administration. * $\mathrm{p}<0.05$ vs. group $H$. Data are means \pm SEM, numbers of rats are in parentheses.

\section{Discussion}

We demonstrate that the NO synthase substrate L-arginine and the phosphodiesterase-5 inhibitor sildenafil added in combination are more potent in the attenuation of HPH compared to treatment by substances given alone. Combined administration was more potent in decreasing mean PAP; it reduced the hypoxia-induced 
remodeling of the prealveolar pulmonary arterioles and significantly reduced right heart hypertrophy. Adding Larginine together with sildenafil resulted in increased plasma concentrations of NOx and cGMP compared to hypoxic non-treated rats.

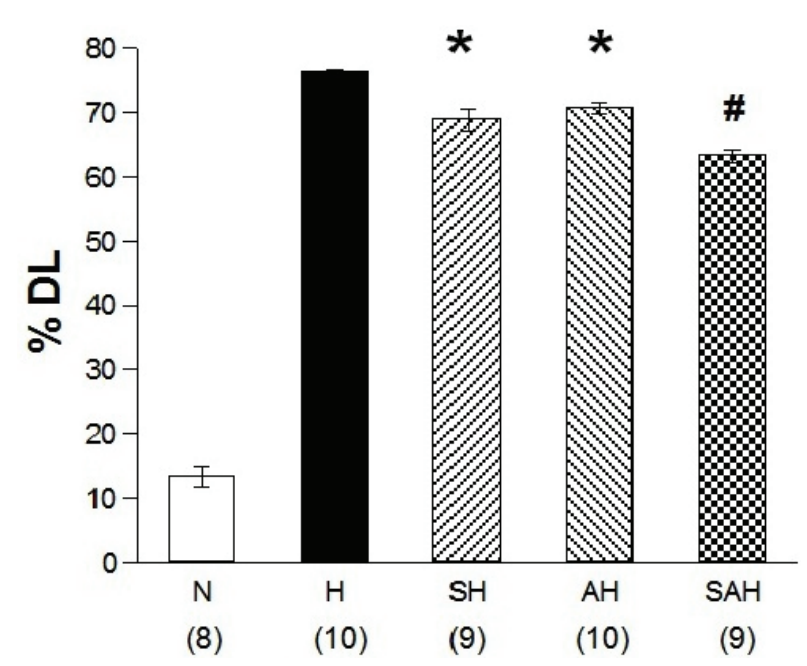

Fig. 3. Ratio of hypertrophied (double laminated) peripheral pulmonary arteries and total number of peripheral pulmonary arteries on section of the right lung. $\mathrm{N}$ - normoxic controls, ambient air $\mathrm{H}$ - hypoxic controls, 3 wks of hypoxia, $\mathrm{SH}-$ hypoxia exposure for 3 wks and sildenafil administration; $\mathrm{AH}$ - hypoxia exposure for $3 \mathrm{wks}$ and L-arginine administration; SAH - hypoxia for 3 wks and sildenafil plus L-arginine administration. $* p<0.001$ vs. group $\mathrm{H}_{;} \# \mathrm{p}<0.001$ vs. group $\mathrm{H}$, group $\mathrm{SH}$ and group $\mathrm{AH}$. Data are means $\pm S E M$, numbers of rats are in parentheses.

In rats treated with L-arginine alone, we found slightly, but significantly attenuated HPH which coincides with increased plasma concentration of cGMP. These data are consistent with the other researchers (Mitani et al. 1997, Fagan et al. 1999). In the present experiment we did not find, however, any effect of Larginine on the right heart hypertrophy induced by chronic hypoxia. Mitani et al. (1997) reported that right heart ventricle hypertrophy reduction during chronic hypoxia with L-arginine administered intraperitonealy was dose dependent: $500 \mathrm{mg} \cdot \mathrm{kg}^{-1}$ of L-arginine was effective but $200 \mathrm{mg} \cdot \mathrm{kg}^{-1}$ had no effect. In our experiment we used $500 \mathrm{mg} \cdot \mathrm{kg}^{-1}$ of L-arginine, but it was given by a gastric gavage. The amount of L-arginine absorbed in the animal gastrointestinal tract could be lower than after intraperitoneal application. The release of insulin and growth hormones by administration of parenteral L-arginine may also be considered (Giugliano et al. 1997). The effect of the L-arginine administered could be explained by its bioavailability and/or by competition with the endogenous asymmetric methylarginines (ADMA). The increased concentration of ADMA was found in patients with pulmonary hypertension (Gorenflo et al. 2001). ADMA acts as an endogenous inhibitor of the NO synthase (Vallance et al. 1992). In conditions of oxidant stress L-arginine supplementation may exacerbate NOS uncoupling, production of superoxide prevails $\mathrm{NO}$ and the radical tissue injury worsens (Druhan et al. 2008).

Results of the studies where authors administered the PDE-5 inhibitor sildenafil alone in HPH are partly controversial. We found lower mean PAP and reduced remodeling of the peripheral pulmonary arterioles compared to hypoxic controls. These results are in accordance with the other researchers (Hanasato et al. 1999, Sebkhi et al. 2003). On the other hand we did not find a reduction of the right heart hypertrophy and we did not find a difference in plasma concentration of the cGMP compared to hypoxic rats. Similar results were found in mice in experiments by Zhao et al. (2001). They found significantly increased cGMP concentration in lung homogenate but not in plasma in chronic hypoxia exposed mice administered with $25 \mathrm{mg} \cdot \mathrm{kg}^{-1}$ per day of sildenafil. In the case of right heart hypertrophy, we found even more controversies in the literature. No comparable experiment was reported which would directly compare the effect of sildenafil administration on hypoxia induced right heart hypertrophy in rat species. Zhao et al. (2001) found significantly decreased right heart hypertrophy in mice after $25 \mathrm{mg}$ per $\mathrm{kg}$ of sildenafil during chronic normobaric hypoxia. Hanasato et al. (1999) used a different PDE-5 inhibitor: E-4010, hypobaric hypoxia and more importantly, they used pretreatment with a PDE-5 inhibitor for 1 day before hypoxia exposition. The other study suggested that sildenafil efficacy on the right heart hypertrophy is not dose-dependent in doses of $3 \mathrm{mg} \cdot \mathrm{kg}^{-1}$ per day and more (Hanasato et al. 1999).

The increase in NO production during the exposure to chronic hypoxia is consistent with several of our former studies (Hampl et al. 2006, Hodyc et al. 2012) and studies of other research groups (see review (Hampl and Herget 2000). NO plays an important role in chronic hypoxia induced structural and functional changes in prealveolar vessels. In the early phase of hypoxic exposure, increased NO production participates with oxygen radicals in the pathogenesis of HPH (Herget et al. 2000, Hampl et al. 2006). In the later phase of hypoxic exposure, increased NO production restricts already developed hypertension (see review Hampl and Herget 
2000). Nitric oxide is not only a vasodilator and smooth muscle cells remodeling inhibitor, it also inhibits platelet aggregation (Adams et al. 1995), as well as decreases endothelial activation of adhesion molecules and proinflammatory cytokines (De Caterina et al. 1995). The other, additional, mechanisms which may be involved in our study should also be considered. The antiaggregatory effect of L-arginine on blood platelets and PDE-5 in pulmonary circulation is thought to limit the vasodilator and antiproliferative effects of the NO (Sebkhi et al. 2003).

In the present study, we focused on the administration of minimal but still effective doses of Larginine and the PDE-5 inhibitor sildenafil to reveal a potentially synergistic effect of the combination of drugs. Our data clearly presents a pure synergistic effect of the combination of the L-arginine and the PDE-5 inhibitor sildenafil in rat model on attenuation of the development of HPH, characterized by significantly decreased mean PAP, significantly decreased remodeling of the peripheral pulmonary arterioles and significantly reduced right heart hypertrophy. Present experimental study suggests novel direction how to enhance the therapeutic effects of PDE-5 inhibitors in hypoxic pulmonary hypertension.

\section{Conflict of Interest}

There is no conflict of interest.

\section{Acknowledgements}

Supported by grants GACR 305/08/108, GAUK 78007, IGA NT/13358. We would like to express our gratitude to our laboratory assistants: Ms Olga Hniličková and Ms Pavlína Smolková for assisting the experiments. In addition, we would like to thank Ms Monika Taylor and Mr Jack Coling for helping us with the manuscript preparation.

\section{References}

ADAMS MR, FORSYTH CJ, JESSUP W, ROBINSON J, CELERMAJER DS: Oral L-arginine inhibits platelet aggregation but does not enhance endothelium-dependent dilation in healthy young men. J Am Coll Cardiol 26: 1054-1061, 1995.

ARCHER SL, HUANG JM, HAMPL V, NELSON DP, SHULTZ PJ, WEIR EK: Nitric oxide and cGMP cause vasorelaxation by activation of a charybdotoxin-sensitive $\mathrm{K}$ channel by cGMP-dependent protein kinase. Proc Natl Acad Sci US A 91: 7583-7587, 1994.

CLOZEL M, HESS P, REY M, IGLARZ M, BINKERT C, QIU C: Bosentan, sildenafil, and their combination in the monocrotaline model of pulmonary hypertension in rats. Exp Biol Med (Maywood) 231: 967-973, 2006.

COHEN AH, HANSON K, MORRIS K, FOUTY B, MCMURTY IF, CLARKE W, RODMAN DM: Inhibition of cyclic 3'-5'-guanosine monophosphate-specific phosphodiesterase selectively vasodilates the pulmonary circulation in chronically hypoxic rats. J Clin Invest 97: 172-179, 1996.

D'ALONZO GE, BARST RJ, AYRES SM, BERGOFSKY EH, BRUNDAGE BH, DETRE KM, FISHMAN AP, GOLDRING RM, GROVES BM, KERNIS JT, ET AL.: Survival in patients with primary pulmonary hypertension. Results from a national prospective registry. Ann Intern Med 115: 343-349, 1991.

DE CATERINA R, LIBBY P, PENG HB, THANNICKAL VJ, RAJAVASHISTH TB, GIMBRONE MA Jr, SHIN WS, LIAO JK: Nitric oxide decreases cytokine-induced endothelial activation. Nitric oxide selectively reduces endothelial expression of adhesion molecules and proinflammatory cytokines. J Clin Invest 96: 60-68, 1995.

DRUHAN LJ, FORBES SP, POPE AJ, CHEN CA, ZWEIER JL, CARDOUNEL AJ: Regulation of eNOS-derived superoxide by endogenous methylarginines. Biochemistry 47: 7256-7263, 2008.

FAGAN JM, REX SE, HAYES-LICITRA SA, WAXMAN L: L-arginine reduces right heart hypertrophy in hypoxiainduced pulmonary hypertension. Biochem Biophys Res Commun 254: 100-103, 1999.

FIKE CD, KAPLOWITZ MR, REHORST-PAEA LA, NELIN LD: L-Arginine increases nitric oxide production in isolated lungs of chronically hypoxic newborn pigs. J Appl Physiol 88: 1797-1803, 2000.

FULTON RM, HUTCHINSON EC, JONES AM: Ventricular weight in cardiac hypertrophy. Br Heart J 14: 413-420, 1952.

GIUGLIANO D, MARFELLA R, VERRAZZO G, ACAMPORA R, COPPOLA L, COZZOLINO D, D'ONOFRIO F: The vascular effects of L-Arginine in humans. The role of endogenous insulin. J Clin Invest 99: 433-438, 1997. 
GORENFLO M, ZHENG C, POGE A, BETTENDORF M, WERLE E, FIEHN W, ULMER HE: Metabolites of the Larginine-NO pathway in patients with left-to-right shunt. Clin Lab 47: 441-447, 2001.

HAMPL V, HERGET J: Role of nitric oxide in the pathogenesis of chronic pulmonary hypertension. Physiol Rev 80: 1337-1372, 2000.

HAMPL V, ARCHER SL, NELSON DP, WEIR EK: Chronic EDRF inhibition and hypoxia: effects on pulmonary circulation and systemic blood pressure. J Appl Physiol 75: 1748-1757, 1993.

HAMPL V, BIBOVA J, BANASOVA A, UHLIK J, MIKOVA D, HNILICKOVA O, LACHMANOVA V, HERGET J: Pulmonary vascular iNOS induction participates in the onset of chronic hypoxic pulmonary hypertension. $A m \mathrm{~J}$ Physiol 290: L11-L20, 2006.

HANASATO N, OKA M, MURAMATSU M, NISHINO M, ADACHI H, FUKUCHI Y: E-4010, a selective phosphodiesterase 5 inhibitor, attenuates hypoxic pulmonary hypertension in rats. Am J Physiol 277: L225L232, 1999.

HERGET J, PALECEK F: Pulmonary arterial blood pressure in closed chest rats. Changes after catecholamines, histamine and serotonin. Arch Int Pharmacodyn Ther 198: 107-117, 1972.

HERGET J, SUGGETT AJ, LEACH E, BARER GR: Resolution of pulmonary hypertension and other features induced by chronic hypoxia in rats during complete and intermittent normoxia. Thorax 33: 468-473, 1978.

HERGET J, WILHELM J, NOVOTNÁ J, ECKHARDT A, VYTÁŠEK R, MRÁZKOVÁ L, OŠŤÁDAL M: A possible role of oxidant tissue injury in the development of pulmonary hypertension. Physiol Res 49: 493-501, 2000.

HODYC D, JOHNSON E, SKOUMALOVÁ A, TKACZYK J, MAXOVÁ H, VÍZEK M, HERGET J: Reactive oxygen species production in the early and later stage of chronic ventilatory hypoxia. Physiol Res 61: 145-151, 2012.

ITOH T, NAGAYA N, FUJII T, IWASE T, NAKANISHI N, HAMADA K, KANGAWA K, KIMURA H: A combination of oral sildenafil and beraprost ameliorates pulmonary hypertension in rats. Am J Respir Crit Care Med 169: 34-38, 2004.

MICHELAKIS E, TYMCHAK W, LIEN D, WEBSTER L, HASHIMOTO K, ARCHER S: Oral sildenafil is an effective and specific pulmonary vasodilator in patients with pulmonary arterial hypertension: comparison with inhaled nitric oxide. Circulation 105: 2398-2403, 2002.

MITANI Y, MARUYAMA K, SAKURAI M: Prolonged administration of L-arginine ameliorates chronic pulmonary hypertension and pulmonary vascular remodeling in rats. Circulation 96: 689-697, 1997.

MOUCHAERS KT, SCHALIJ I, VERSTEILEN AM, HADI AM, VAN NIEUW AMERONGEN GP, VAN HINSBERGH VW, POSTMUS PE, VAN DER LAARSE WJ, VONK-NOORDEGRAAF A: Endothelin receptor blockade combined with phosphodiesterase-5 inhibition increases right ventricular mitochondrial capacity in pulmonary arterial hypertension. Am J Physiol 297: H200-H207, 2009.

MURAD F: Cyclic guanosine monophosphate as a mediator of vasodilation. J Clin Invest 78: 1-5, 1986.

PALMER RM, ASHTON DS, MONCADA S: Vascular endothelial cells synthesize nitric oxide from L-arginine. Nature 333: 664-666, 1988.

PRESTON IR, HILL NS, GAMBARDELLA LS, WARBURTON RR, KLINGER JR: Synergistic effects of ANP and sildenafil on cGMP levels and amelioration of acute hypoxic pulmonary hypertension. Exp Biol Med (Maywood) 229: 920-925, 2004.

SATOH M, SATOH A: 3-Hydroxy-3-methylglutaryl (HMG)-COA reductase inhibitors and phosphodiesterase type V inhibitors attenuate right ventricular pressure and remodeling in a rat model of pulmonary hypertension. J Pharm Pharm Sci 11: 118s-130s, 2008.

SEBKHI A, STRANGE JW, PHILLIPS SC, WHARTON J, WILKINS MR: Phosphodiesterase type 5 as a target for the treatment of hypoxia-induced pulmonary hypertension. Circulation 107: 3230-3235, 2003.

SINGH SB, SELVAMURTHY W: Effect of intermittent chronic exposure to hypoxia on feeding behaviour of rats. Int $J$ Biometeorol 37: 200-202, 1993.

STUEHR DJ, KWON NS, NATHAN CF, GRIFFITH OW, FELDMAN PL, WISEMAN J: N omega-hydroxy-Larginine is an intermediate in the biosynthesis of nitric oxide from L-arginine. J Biol Chem 266: 6259-6263, 1991. 
SUN Y, ZHU Z, LANGNAS AN, GRANT WJ, BOTHA JF, ZHAO Y, SUDAN DL, MERCER DF: Plasma nitrite and nitrate levels as a noninvasive marker of pathology after human small bowel transplantation. Transplantation 89: 307-311, 2010.

VALLANCE P, LEONE A, CALVER A, COLLIER J, MONCADA S: Accumulation of an endogenous inhibitor of nitric oxide synthesis in chronic renal failure. Lancet 339: 572-575, 1992.

XUE C, RENGASAMY A, LE CRAS TD, KOBERNA PA, DAILEY GC, JOHNS RA: Distribution of NOS in normoxic vs. hypoxic rat lung: upregulation of NOS by chronic hypoxia. Am J Physiol 267: L667-L678, 1994.

ZHAO L, MASON NA, MORRELL NW, KOJONAZAROV B, SADYKOV A, MARIPOV A, MIRRAKHIMOV MM, ALDASHEV A, WILKINS MR: Sildenafil inhibits hypoxia-induced pulmonary hypertension. Circulation 104: 424-428, 2001.

ZHAO L, SEBKHI A, ALI O, WOJCIAK-STOTHARD B, MAMANOVA L, YANG Q, WHARTON J, WILKINS MR: Simvastatin and sildenafil combine to attenuate pulmonary hypertension. Eur Respir J 34: 948-957, 2009. 